\title{
FRACIONAMENTO DE COBRE EM PROTEÍNAS DO PLASMA, MÚSCULO E FÍGADO DE TILÁPIA DO NILO
}

Renato C. F. Neves, Paula M. Lima e Welder A. Baldassini

Faculdade de Medicina Veterinária e Zootecnia, Universidade Estadual Paulista, CP 560, 18618-970 Botucatu - SP, Brasil

Felipe A. Santos, Paula M. Moraes* e Gustavo R. Castro

Departamento de Química e Bioquímica, Instituto de Biociências, Universidade Estadual Paulista, CP 510, 18618-970 Botucatu

- SP, Brasil

Pedro M. Padilha

Departamento de Química e Bioquímica, Instituto de Biociências, Universidade Estadual Paulista, CP 510, 18618-970 Botucatu - SP / Instituto Nacional de Ciência e Tecnologia de Bioanalítica / Universidade Estadual de Campinas, CP 6154, 13084-971

Campinas - SP, Brasil

Recebido em 18/4/11; aceito em 7/9/11; publicado na web em 3/11/11

COPPER FRACTIONATION IN PROTEINS FROM PLASMA, MUSCLE AND LIVER OF NILE TILAPIA. Copper fractionation in plasma, muscle and liver of Nile tilapia was performed after protein separation by 2D-PAGE. SR XRF analysis indicated the presence of copper in three protein spots of plasma, and in two protein spots of muscle and liver, respectively. Copper ions were found to be distributed mostly in proteins that had a molar mass of less than $54 \mathrm{kDa}$ and greater than $13 \mathrm{kDa}$ and a $\mathrm{pI}$ in the 5.3-9.3 range. The copper concentration bound to these proteins was determined by GFAAS which showed concentrations in the $1.20-4.82 \mathrm{mg} \mathrm{g}^{-1}$ range.

Keywords: Nile tilapia; metalloproteins; metallomics.

\section{INTRODUÇÃO}

Na nutrição de peixes, como de outros animais, o cobre é elemento dietético essencial. Tanto a deficiência quanto o excesso desse mineral podem causar alterações nas funções fisiológicas e na resposta imunológica, aumentando a susceptibilidade do animal a infecções. ${ }^{1,2}$ Esse mineral possui importantes funções no organismo dos peixes, sendo necessário no metabolismo de vários nutrientes e como constituinte de diversas enzimas. Destaca-se como referência de sua importância a participação como cofator, dentre outras, da enzima ALA-desidrogenase, a qual participa na síntese do heme em sua incorporação no pigmento hemoglobina. Além disso, é indiretamente responsável também pela formação do colágeno e da elastina, e pela conversão da tirosina em melanina em destruição de ânions superóxido, que são espécies reativas do oxigênio, potencialmente destrutivos para as células. ${ }^{1-4}$

A importância dos minerais como componentes estruturais e funcionais dos organismos vivos e o fato de grande parte das proteínas e enzimas requererem a presença de um íon metálico para realizar alguma atividade biológica levaram os pesquisadores que trabalham com aquicultura a desenvolverem trabalhos relacionados à influência das metaloproteínas na fisiologia, genética e nutrição de peixes. ${ }^{4-9}$

Nesse contexto, atualmente, o desenvolvimento de metodologias analíticas que permitam uma avaliação segura das metaloproteínas e/ou proteínas ligadas a metais presentes no sangue e em tecidos de animais se tornou fundamental. Principalmente, em relação aos chamados microminerais, como o cobre, os quais apresentam faixas de essencialidade e toxicidade muito próximas e que são transportados em nível celular por diferentes proteínas. Considerando a importância que essas biomoléculas exercem sobre as atividades biológicas dos seres vivos, uma nova área científica denominada metalômica foi proposta recentemente e permitiu a integração de estudos tradicio-

*e-mail: paulamartin@ibb.unesp.br nalmente analíticos com estudos inorgânicos e bioquímicos. O estudo da metalômica das diferentes espécies de peixes poderá fornecer informações valiosas sobre como um íon metálico está distribuído e coordenado às proteínas, como também da concentração individual da espécie metálica, contribuindo assim na elucidação dos aspectos fisiológicos e funcionais dessas biomoléculas. ${ }^{10-13}$ Recentemente foram publicados por pesquisadores brasileiros os primeiros resultados obtidos no estudo metaloproteômico da espécie de peixe tilápia do Nilo. ${ }^{14,15}$ Nessas publicações, os autores, utilizando 2D-PAGE no fracionamento das proteínas de plasma e tecido hepático, identificaram, por SR XRF, manganês e zinco em 10 proteínas do plasma e cálcio, ferro e zinco em 26 proteínas do fígado. Essas metaloproteínas apresentaram valores de massa molar de 12 a $70 \mathrm{kDa}$, com ponto isoelétrico (pI) entre 4,7 e 9,4.

Com base no exposto, o presente trabalho teve como objetivo investigar cobre, qualitativa e quantitativamente, em spots de proteínas de amostras de plasma, músculo e fígado de tilápia do Nilo (Oreochromis niloticus) por SR XRF e GFAAS, após separação por 2D-PAGE. Os dados apresentados no presente trabalho dão continuidade aos estudos iniciais da metalômica dessa espécie de peixe. ${ }^{14,15}$

\section{PARTE EXPERIMENTAL}

\section{Equipamentos}

Além de vidrarias convencionalmente utilizadas em laboratório de Química Analítica, foram empregados os seguintes equipamentos e acessórios: espectrofotômetro UV/visível, marca ThermoSpectronic, modelo Genesys 6, (Rochester, EUA), sistema para eletroforese 2D-PAGE, marca GE Healthcare, modelo Ettan ${ }^{\mathrm{TM}}$ Daltsix (Uppsala, Suécia), sistema para focalização isoelétrica, marca Amersham Biosciences, modelo EPS1001 (Uppsala, Suécia), Scanner (GE Healthcare), espectrômetro de absorção atômica Shimadzu, modelo AA-6800 (Tokyo, Japão) e forno de micro-ondas Provecto Analítica, modelo DGT 100 plus (Campinas/São Paulo, Brasil). 


\section{Reagentes e soluções}

Água ultrapura $\left(18,2 \mathrm{M} \Omega \mathrm{cm}^{-1}\right)$ obtida pelo sistema Elga modelo Purelab Ultra Ionic foi utilizada em todo o trabalho no preparo das soluções. Ácidos acético (J. T. Backer) e fosfórico (Mallinckodt) de pureza analítica, nítrico e clorídrico (Merck) de grau espectroscópico foram utilizados em todo o trabalho no preparo das soluções usadas nas separações eletroforéticas. Todos os solventes orgânicos utilizados (e.g. etanol, acetona, metanol) foram de pureza analítica e de procedência Merck. As soluções utilizadas nas separações eletroforéticas e nas determinações de proteína total foram preparadas com reagentes de pureza analítica de procedência Amersham Biosciences. Todas as soluções foram estocadas em frascos de polipropileno e/ou vidro, sendo que as soluções utilizadas nas separações eletroforéticas foram guardadas em refrigerador a $4{ }^{\circ} \mathrm{C}$ ou em freezer a $-20{ }^{\circ} \mathrm{C}$.

Todos os frascos de estocagem das soluções tampões, soluções extratoras, padrões proteicos e vidrarias foram lavados com ácido nítrico $10 \% \mathrm{v} / \mathrm{v}$ por $24 \mathrm{~h}$ e, em seguida, enxaguados com água ultrapura e secos por jatos de ar puro antes da utilização.

\section{Coleta e preparo das amostras}

As amostras de plasma, músculo e fígado foram obtidas a partir de juvenis de tilápia do Nilo (Oreochromis niloticus) criadas no Laboratório de Nutrição de Organismos Aquáticos, Faculdade de Medicina Veterinária e Zootecnia, Universidade Estadual Paulista, Botucatu/SP. Os peixes foram anestesiados com solução de benzocaína (100 mg $\left.\mathrm{L}^{-1}\right)$ para coleta de sangue do vaso caudal com auxílio de seringa de 1,0 mL para obtenção da amostra de plasma. Após a coleta, o sangue foi transferido para tubos do tipo Eppendorf, o qual continha $\mathrm{K}_{2}$ EDTA $3,0 \%(\mathrm{~m} / \mathrm{v})$ que foi utilizado como anticoagulante. O sangue foi então centrifugado a $13000 \mathrm{rpm}$ durante $5 \mathrm{~min}$ a $4{ }^{\circ} \mathrm{C}$ em ultracentrífuga refrigerada (BioAgency) para obtenção do plasma; em seguida, essas amostras foram armazenadas a $-20{ }^{\circ} \mathrm{C}$. Após este procedimento, os peixes anestesiados com benzocaína foram eutanasiados para retirada de filés do músculo e fígado inteiro. As amostras de músculo e fígado foram então transferidas para frascos de polipropileno de $15 \mathrm{~mL}$ e armazenadas a $-80{ }^{\circ} \mathrm{C}$.

\section{Preparação das amostras para eletroforese}

Aproximadamente $1 \mathrm{~g}$ das amostras de músculo e fígado foram maceradas separadamente em água ultrapura, com auxílio de almofariz e pistilo. Em seguida, os extratos contendo as proteínas de músculo e fígado foram separados da parte sólida por centrifugação a 13000 rpm e a $4^{\circ} \mathrm{C}$ durante $5 \mathrm{~min}$, em ultracentrífuga refrigerada. Os extratos proteicos obtidos dessas amostras foram transferidos para tubos do tipo Eppendorf e utilizados posteriormente para quantificação dos teores proteicos e corridas eletroforéticas.

As amostras de plasma e o extrato proteico de tecido hepático foram submetidos a um processo de remoção de albumina por meio do uso de um kit de remoção de albumina (Millipore), visto que essas amostras apresentam altas concentrações dessa proteína. ${ }^{16,17}$ Após o procedimento de remoção de albumina, os extratos proteicos do plasma e do tecido hepático, juntamente com o extrato proteico das amostras de tecido muscular, foram tratados com solução gelada de acetona $80 \%$ (v/v) na proporção 1:4 (amostra: acetona) para precipitação das proteínas. Essa precipitação foi conduzida durante $3 \mathrm{~h}$ a 4 ${ }^{\circ} \mathrm{C}$, garantindo que a precipitação ocorresse de maneira quantitativa. Em seguida, os precipitados proteicos foram centrifugados a 13000 rpm em ultracentrífuga refrigerada por 10 min e o sobrenadante foi retirado. Os precipitados proteicos foram lavados duas vezes com a solução de acetona gelada utilizada para a precipitação. Após estes procedimentos parte dos precipitados foi ressolubilizado em solução de $\mathrm{NaOH}$ a $0,50 \mathrm{~mol} \mathrm{~L}^{-1}$ para quantificação do teor total de proteínas, e outra parte foi ressolubilizada em tampão contendo ureia a $7 \mathrm{~mol}$ $\mathrm{L}^{-1}$, tioureia a $2 \mathrm{~mol} \mathrm{~L}^{-1}, \mathrm{CHAPS}$ a $2 \%(\mathrm{~m} / \mathrm{v})$, anfólitos de $\mathrm{pH} 3$ a 10 a $0,5 \%(\mathrm{v} / \mathrm{v})$, azul de bromofenol a $0,002 \%(\mathrm{~m} / \mathrm{v})$ e $2,8 \mathrm{mg}$ de DTT para ser utilizada nas separações eletroforéticas. ${ }^{18}$

\section{Determinação da concentração de proteínas totais}

A concentração de proteínas totais nos extratos proteicos foi determinada de acordo com o método de Bradford ${ }^{19}$ Curvas analíticas de calibração foram feitas com padrões de 25 a $100 \mu \mathrm{g} \mathrm{mL}^{-1}$ a partir de solução padrão estoque de $500 \mu \mathrm{g} \mathrm{mL}^{-1}$ de albumina de soro bovino. O procedimento experimental utilizado foi: em cubetas de vidro foram adicionados $200 \mu \mathrm{L}$ de padrão e/ou amostra diluída apropriadamente, e 2,5 mL do reagente de Bradford. Após 5 min de reação, as leituras de absorbância foram medidas a $595 \mathrm{~nm}$ em espectrofotômetro.

\section{Separações eletroforéticas}

Antes do início das separações eletroforéticas, volumes de $250 \mu \mathrm{L}$ dos extratos proteicos (contendo $1 \mu \mathrm{g} \mu \mathrm{L}^{-1}$ de proteína total) foram aplicados em fitas de $13 \mathrm{~cm}$ que continham o gel pré-fabricado com os anfólitos imobilizados de $\mathrm{pH} 4$ a 7 para amostras do plasma e de pH 3 a 10 para amostras de músculo e tecido hepático. Essas fitas, utilizadas na etapa de focalização isoelétrica, foram colocadas em um aparato sobre o qual permaneceram por $12 \mathrm{~h}$ à temperatura ambiente para serem hidratadas com o extrato proteico. Além do extrato proteico, foram adicionados também cerca de $900 \mu \mathrm{L}$ de óleo mineral sobre essas fitas, a fim de evitar o ressecamento das mesmas. Após este período, a fita hidratada foi levada ao sistema para focalização isoelétrica para corrida em primeira dimensão da eletroforese bidimensional, utilizando a seguinte programação de tensão: ${ }^{14,15}$ etapa 1 $=500 \mathrm{~V}$, com acúmulo de $500 \mathrm{Vh}$; etapa $2=1000 \mathrm{~V}$, com acúmulo de $800 \mathrm{Vh}$; etapa $3=10000 \mathrm{~V}$, com acúmulo de $11300 \mathrm{Vh}$; etapa 4 $=10000 \mathrm{~V}$, com acúmulo de $3000 \mathrm{Vh}$.

O programa de separação em primeira dimensão durou em média 4,5 h. Após o término da focalização isoelétrica, a fita com as proteínas separadas em função do pI foi equilibrada em duas etapas. $\mathrm{Na}$ primeira, foram utilizados $10 \mathrm{~mL}$ de solução contendo ureia $6 \mathrm{~mol} \mathrm{~L}^{-1}$, SDS 2\% (m/v), glicerol 30\% (v/v), Tris- $\mathrm{HCl} 50 \mathrm{mmol} \mathrm{L}^{-1}$, azul de bromofenol 0,002\% (m/v) e DTT 1\% (m/v). Esta etapa denominada redução tem a finalidade de manter as proteínas em suas formas reduzidas. Na segunda etapa foi utilizada uma solução de composição similar, porém, substituindo-se o DTT por iodoacetamida 2,5\% $(\mathrm{m} / \mathrm{v})$. Esta etapa é denominada alquilação e sua finalidade é alquilar os grupos tióis das proteínas, prevenindo que elas sejam reoxidadas durante o processo eletroforético. Cada uma destas etapas durou 15 min e foi feita sob leve agitação em mesa agitadora. ${ }^{14-18}$

Após a etapa de equilíbrio das fitas foi feita a segunda dimensão do processo eletroforético (SDS-PAGE). A fita de proteínas do plasma foi aplicada em gel de poliacrilamida $10 \%(\mathrm{~m} / \mathrm{v})$ e as fitas de músculo e fígado em gel de poliacrilamida $12,5 \%(\mathrm{~m} / \mathrm{v})$, previamente preparados em placa de vidro de 180 x 160 x 1,5 mm. Os geis de poliacrilamida foram preparados a partir das seguintes soluções: acrilamida, N,N'-metilenobisacrilamida, tris-hidroximetil amino metano, dodecil sulfato de sódio (SDS), N,N',N,N'-tetrametilenodiamina (TEMED), ácido clorídrico e persulfato de amônio. Foi colocado sobre o gel de poliacrilamida, ao lado da fita, um pedaço de papel de filtro ao qual foram aplicados $10 \mu \mathrm{L}$ de padrão de massa molar contendo as proteínas $\beta$-fosforilase (97,0 kDa), albumina (66,0 kDa), ovoalbumina (45,0 $\mathrm{kDa})$, anidrase carbônica (30,0 kDa), inibidor de tripsina (20,1 kDa) e $\alpha$-lactoalbumina $(14,4 \mathrm{kDa})$. A fita e o papel de filtro foram vedados 
com solução quente de agarose $0,5 \%(\mathrm{~m} / \mathrm{v})$ em tampão adequado, de modo a garantir o contato destes com o gel de poliacrilamida. Em seguida, a corrida eletroforética em segunda dimensão foi efetuada em sistema para eletroforese 2D-PAGE, em duas etapas, utilizando a seguinte programação: ${ }^{14,15}$ etapa $1-$ tensão $(V)=90$, corrente elétrica $(\mathrm{mA})=25$, potência $(\mathrm{W})=100$, tempo $(\mathrm{h})=0,5 ;$ etapa $2-$ tensão $(\mathrm{V})$ $=250$, corrente elétrica $(m A)=25$, potência $(W)=100$, tempo $(h)=5$.

Após o período de corrida (aproximadamente 5,5 h) as proteínas foram fixadas durante $1 \mathrm{~h}$ empregando-se solução contendo ácido acético $10 \%$ (v/v) e etanol $40 \%(\mathrm{v} / \mathrm{v})$. Posteriormente, as proteínas foram reveladas empregando-se o corante coomassie coloidal, que consiste em uma solução de sulfato de amônio $8 \%(\mathrm{~m} / \mathrm{v})$, ácido fosfórico $1,6 \%$ (v/v), azul de coomassie G-250 0,08\% (m/v) e metanol $25 \%$ (v/v). O corante ficou em contato com o gel durante $72 \mathrm{~h}$ e depois foi removido por sucessivas lavagens com água ultrapura. ${ }^{20}$ Os geis obtidos, feitos em triplicata para os três tipos de amostra, foram escaneados em scanner GE Healthcare. As imagens escaneadas foram analisadas utilizando o programa ImageMaster 2D Platinum 7.0 para se obter a correlação entre as repetições de geis, a contagem de spots em cada réplica de gel e a estimativa da massa de proteína presente nos spots.

\section{Determinação qualitativa de cobre por SR XRF nos spots proteicos}

As determinações qualitativas de cobre nos spots proteicos das amostras de plasma, músculo e fígado foram feitas em linha de fluorescência de raios-X com radiação síncrotron, disponível no Laboratório Nacional de Luz Síncrotron, em Campinas-SP/Brasil. Os spots de proteínas foram retirados do gel com o auxílio de uma ponteira de pipeta, secos com lâmpada de infravermelho durante 20 min e fixados em plataforma de alumínio. Após serem estabelecidas as condições de análise, o mapeamento do cobre foi realizado por irradiação do spot por $200 \mathrm{~s}$ em dois pontos. Os espectros coletados foram processados por meio do programa AXIL, que permite corrigir a variação da intensidade do feixe da radiação síncrotron, fazendo-se a normalização da área dos picos das espécies químicas detectadas pela contagem do pico de argônio. ${ }^{21}$

\section{Determinação quantitativa de cobre por GFAAS nos spots proteicos}

A quantificação de cobre nos spots proteicos foi feita por espectrometria de absorção atômica em forno de grafite, após a separação dos spots do gel com o auxílio de uma ponteira de pipeta e posterior mineralização por digestão ácida. Nessas determinações foi utilizado espectrômetro de absorção atômica Shimadzu, modelo AA-6800, equipado com corretor de absorção de fundo self-reverse (SR), tubo de grafite pirolítico com plataforma integrada e amostrador automático ASC-6100. Foi utilizada lâmpada de cátodo oco de cobre Shimadzu, operada com $10 \mathrm{~mA}$ de corrente. O comprimento de onda empregado foi de $324,7 \mathrm{~nm}$, com resolução espectral de $0,5 \mathrm{~nm}$. Argônio foi usado como gás inerte, mantendo-se um fluxo constante de $1 \mathrm{~L} \mathrm{~min}^{-1}$ durante todo o programa de aquecimento, exceto na etapa de atomização, na qual o fluxo de gás foi interrompido. Os sinais de absorbância foram medidos em área de pico. ${ }^{3,4,22}$

\section{RESULTADOS E DISCUSSÃO}

\section{Determinação da concentração de proteínas totais nas amostras}

As determinações do teor total de proteína nos extratos proteicos das amostras foram feitas para se obter a melhor massa proteica a ser aplicada nos geis das corridas eletroforéticas por 2D-PAGE, levandose em consideração a concentração do gel. Os resultados dessas determinações indicaram que os extratos proteicos das amostras de plasma, músculo e fígado continham $25,7 \pm 0,27 ; 25,1 \pm 0,17$; e 24,8 $\pm 0,19 \mathrm{mg} \mathrm{mL}^{-1}$, respectivamente.

Com base nesses resultados, volumes de $10 \mu \mathrm{L}$ dos extratos das amostras foram diluídos com água ultrapura para um volume de 250 $\mu \mathrm{L}$ e aplicados nas tiras contendo geis pré-fabricados para a etapa de IEF, o que corresponde a uma massa de aproximadamente 250 $\mu \mathrm{g}$ de proteína.

\section{Otimização das separações eletroforéticas}

Na eletroforese 2D-PAGE cada mancha no gel, ou mais comumente denominado spot, representa uma única proteína. ${ }^{23}$ Todas as corridas eletroforéticas dos extratos das amostras foram feitas em triplicata. Análises de correlações e a contagem do número de spots também foram feitas entre as repetições dos geis. As Figuras 1-3 mostram os geis obtidos a partir dos extratos proteicos das amostras

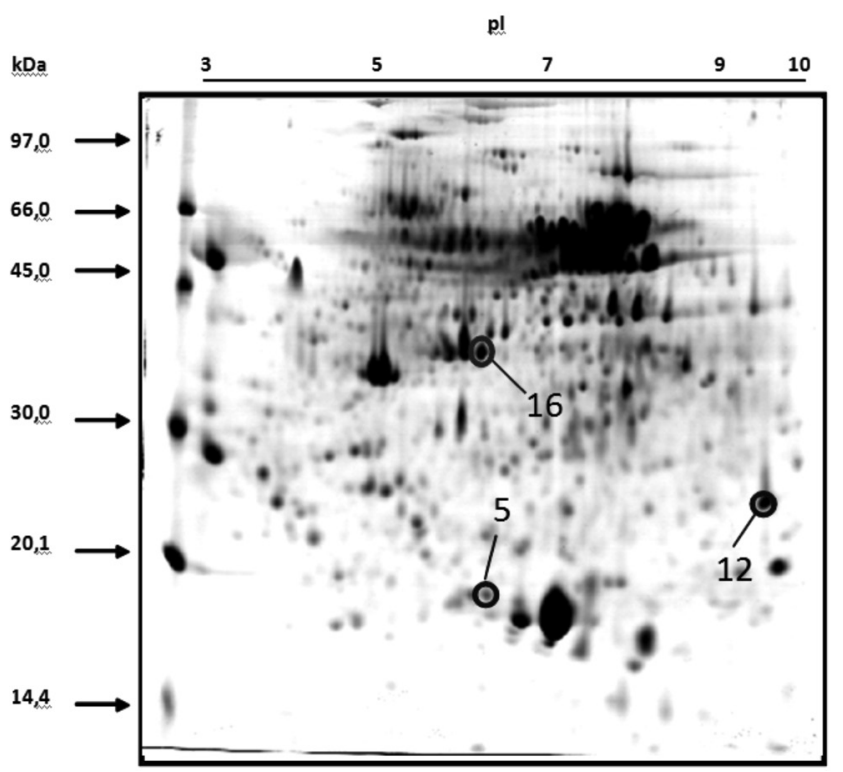

Figura 1. Gel de poliacrilamida $10 \%(\mathrm{~m} / \mathrm{v})$ do plasma de tilápia do Nilo com pI de 4 a 7 e massa molar de proteína entre 20,1 e 97,0 kDa

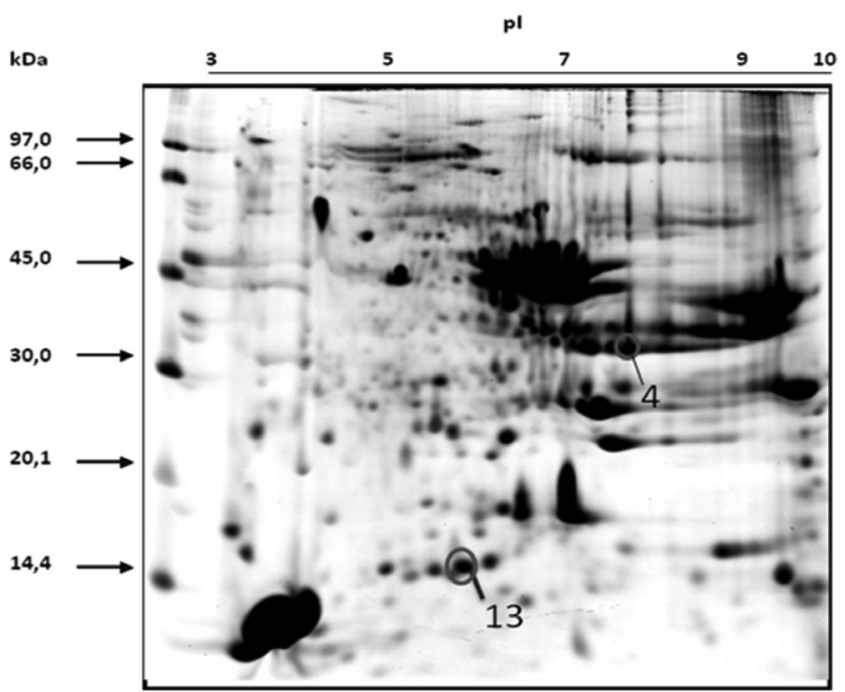

Figura 2. Gel de poliacrilamida $12,5 \%(\mathrm{~m} / \mathrm{v})$ do músculo de tilápia do Nilo com pI de 3 a 10 e massa molar de proteína entre 14,4 e $97 \mathrm{kDa}$ 
pl

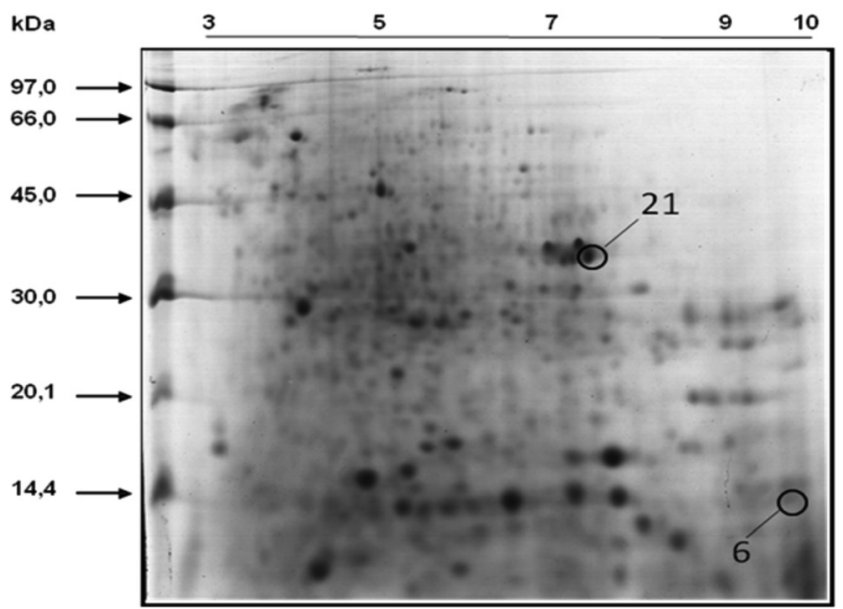

Figura 3. Gel de poliacrilamida $12,5 \%(\mathrm{~m} / \mathrm{v})$ do tecido hepático de tilápia do Nilo com pI de 3 a 10 e massa molar de proteína entre 14,4 e 97 kDa

de plasma, músculo e fígado, com os spots proteicos nos quais foi detectado cobre por SR XRF destacados com um círculo.

Conforme mostram as Figuras 1-3, os geis das amostras de plasma, músculo e fígado apresentaram grande diversidade de spots proteicos, alguns mais intensos, com pI e massa molar entre 3-9,5 e 20-70 kDa para os geis de plasma; 3,5-9 e 10-70 kDa para o músculo e, 4-8 e 10-70 kDa para o fígado. As análises das imagens das repetições dos geis das amostras de plasma, músculo e fígado apresentaram correlações de 89,5; 71,7 e 66,45\%, com número médio de spots de $575 \pm 13,480 \pm 16$ e $505 \pm 12$, respectivamente.

\section{Avaliação qualitativa de cobre por SR XRF nos spots proteicos}

A avaliação qualitativa de cobre ligado às proteínas dos spots proteicos foi feita por SR XRF, considerando-se a sensibilidade dessa técnica e que possivelmente as concentrações de cobre nos diversos spots estariam na faixa de $\mu \mathrm{g} \mathrm{kg}{ }^{-1}$ ou mg kg-1 ${ }^{-1}$ As Figuras 4-6 apresentam os gráficos dos espectros de fluorescência obtidos nas análises por SR XRF dos spots proteicos 5, 13 e 6 das amostras de plasma, músculo e fígado de tilápia do Nilo, respectivamente.

De forma geral, todos os espectros obtidos nas análises por SR $\mathrm{XRF}$ apresentaram fundos contínuos intensos. Tais fundos se devem, principalmente, ao espalhamento Compton dos raios-X incidentes sobre a matriz do gel, o qual pode mascarar os sinais do elemento de

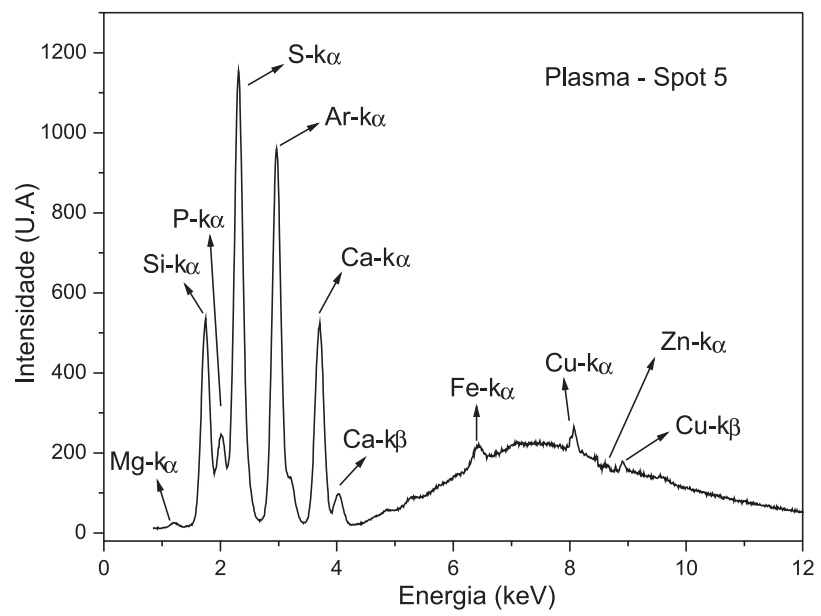

Figura 4. Espectro de fluorescência de raios-X com radiação síncrotron obtido para o spot proteico 5 do plasma de tilápia do Nilo

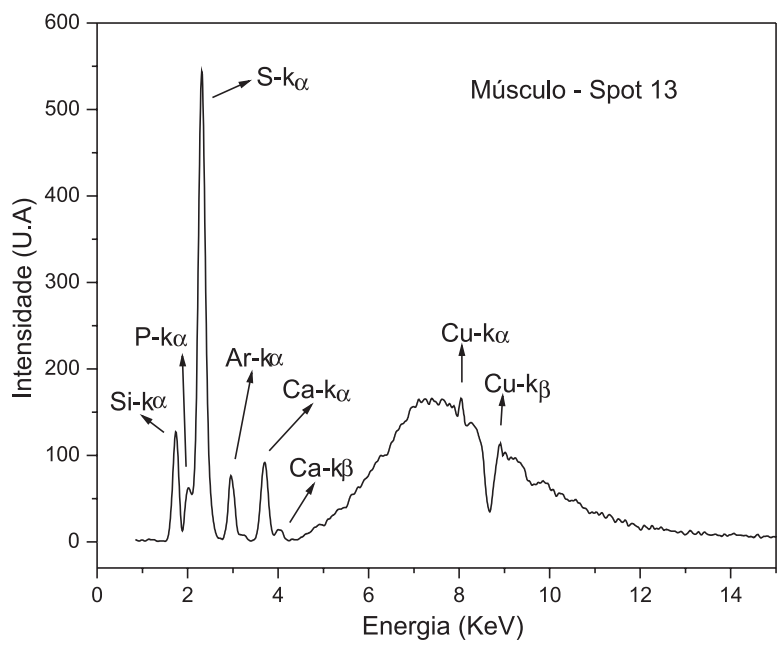

Figura 5. Espectro de fluorescência de raios-X com radiação síncrotron obtido para o spot proteico 13 do músculo de tilápia do Nilo

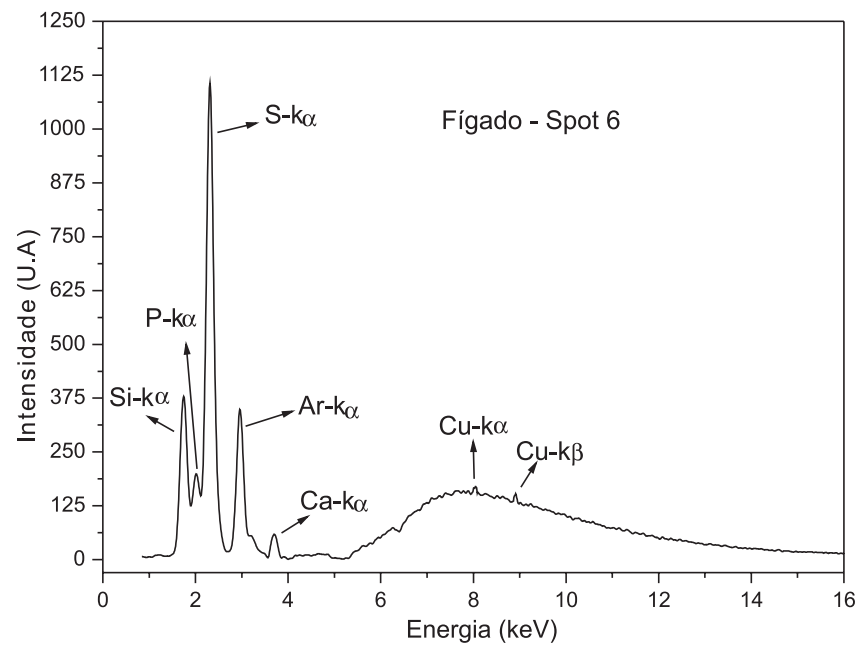

Figura 6. Espectro de fluorescência de raios-X com radiação síncrotron obtido para o spot proteico 6 do tecido hepático de tilápia do Nilo

interesse..$^{22,23}$ Dessa forma, utilizando os valores das áreas dos picos normalizados (após desconto do branco analítico) dos espectros de SR $\mathrm{XRF}$, foi possível identificar cobre $\left(\mathrm{k}_{\alpha 1}=8,047, \mathrm{k}_{\beta 1}=8,904\right)$ ligado às proteínas dos spots destacados com um círculo, apresentados nas Figuras 1-3.

Como pode ser visto nos espectros das Figuras 4-6, além do cobre foi detectada a presença de enxofre e fósforo, não metais que podem estar presentes na estrutura da proteína do spot analisado. Outros íons metálicos detectados foram cálcio, cobalto, ferro, magnésio e zinco. A presença de mais de um íon metálico/metaloide em spots de proteínas é aceitável, já que uma única metaloproteína ou proteína metal ligante pode ter vários sítios ativos formados por átomos de íons de diferentes elementos. ${ }^{24}$ Os picos de grande intensidade relativos ao argônio $\left(\mathrm{k}_{\alpha 1}=\right.$ $2,957)$ e ao silício $\left(\mathrm{k}_{\alpha 1}=1,740\right)$, que aparecem em todos os espectros, são esperados pois neste caso o silício está presente na fita em que é fixada a amostra do spot proteico e o argônio está presente no ar ambiente a uma taxa constante de $0,934 \%$ v/v. ${ }^{25,26}$ Na Tabela 1 são apresentados os spots nos quais foi identificada a presença de cobre.

Com base nos resultados apresentados na Tabela 1 pode-se sugerir a presença de cobre em três spots proteicos de plasma e em dois spots proteicos de músculo e fígado. Sendo que, de forma geral, os íons cobre identificados por SR XRF estão ligados a proteínas com massa molar entre 54 e $13 \mathrm{kDa}$ e com pI de 5,3 a 9,3. 
Tabela 1. Massa molar (Mm) e ponto isoelétrico (pI) de proteínas do pool de amostras de plasma, músculo e fígado de tilápia do Nilo separadas por 2D-PAGE que apresentaram cobre ligado em suas estruturas

\begin{tabular}{lccc}
\hline Amostras & Spot & Mm $(\mathrm{kDa})$ & $\mathrm{pI}$ \\
\hline Plasma & 5 & 27,2 & 5,4 \\
& 12 & 37,1 & 6,8 \\
Músculo & 16 & 53,8 & 5,3 \\
& 4 & 35,1 & 7,7 \\
Fígado & 13 & 14,8 & 6,1 \\
& 6 & 13,6 & 9,3 \\
& 21 & 37,7 & 7,4
\end{tabular}

\section{Avaliação quantitativa de cobre nos spots proteicos das amostras}

Após a identificação da presença de cobre por SR XRF nos spots das amostras obtidos por 2D-PAGE, foi feita a quantificação desse elemento por GFAAS depois da mineralização ácida dos spots proteicos. A validação do método utilizado na quantificação do cobre foi feita por meio da determinação desse analito em material certificado Corn Bran RM 8433 - National Institute of Standard and Technology. ${ }^{27}$ As concentrações de cobre nos spots proteicos foram feitas considerando a estimativa da massa de proteína obtida por densidade óptica utilizando-se o programa ImageMaster 2 D Platinum versão 7.0. Na Tabela 2 são apresentadas as concentrações de cobre determinadas nos spots proteicos.

Tabela 2. Concentração de cobre e estimativa das massas de proteínas determinadas $(\mathrm{n}=3)$ nos spots proteicos do pool de amostras de plasma, músculo e fígado de tilápia do Nilo, nos quais foi detectada a presença desse elemento por SR XRF

\begin{tabular}{lccc}
\hline Amostras & Spot & Cobre $\left(\mathrm{mg} \mathrm{g}^{-1}\right)$ & Proteína $(\mu \mathrm{g})$ \\
\hline Plasma & 5 & $4,52 \pm 0,09$ & $3,40 \pm 0,07$ \\
& 12 & $3,60 \pm 0,08$ & $2,80 \pm 0,06$ \\
& 16 & $1,20 \pm 0,03$ & $2,20 \pm 0,05$ \\
Músculo & 4 & $3,50 \pm 0,07$ & $3,10 \pm 0,06$ \\
& 13 & $4,43 \pm 0,10$ & $1,90 \pm 0,04$ \\
Fígado & 6 & $4,82 \pm 0,12$ & $1,60 \pm 0,03$ \\
& 21 & $1,80 \pm 0,05$ & $1,40 \pm 0,03$ \\
\hline
\end{tabular}

Resultados obtidos na determinação de cobre em padrão certificado Corn Bran NIST RM 8433: valor determinado $=2,44 \pm 0,05 \mathrm{mg} \mathrm{kg}^{-1}$; valor certificado $=$ $2,47 \pm 0,4 \mathrm{mg} \mathrm{kg}{ }^{-1} \cdot{ }^{27}$ Limite de detecção do método (LOD) $=0,24 \mu \mathrm{g} \mathrm{L}^{-1}$; limite de quantificação do método $(\mathrm{LOQ})=0,74 \mu \mathrm{g} \mathrm{\textrm {L } ^ { - 1 }}{ }^{27}$

Analisando-se os resultados mostrados na Tabela 2, observa-se que as concentrações de cobre determinadas nos spots proteicos das amostras apresentam valores entre $1,20 \mathrm{e} 4,82 \mathrm{mg} \mathrm{g}^{-1}$. No entanto, os resultados apresentados na Tabela 2 não fornecem muita informação, porque não se sabe de quais proteínas se tratam. Dessa forma, foi feita a conversão da estimativa das massas de proteínas e das massas de cobre para quantidades de moléculas de proteína e de átomos de cobre, considerando as massas molares das proteínas e do cobre e que $1 \mathrm{kDa}$ $=1,661 \times 10^{-24} \mathrm{~g}$. Esses cálculos possibilitaram a estimativa de quantos átomos de cobre estariam presentes por molécula de proteína. ${ }^{10,11,2.3}$ Os resultados obtidos nesses cálculos são mostrados na Tabela 3.

Com base nos resultados apresentados na Tabela 3 foi possível estimar a proporção de cobre por molécula de proteína. Dessa forma,
Tabela 3. Estimativa do número de moléculas de proteína contendo cobre ligado, número de átomos de cobre por spot proteico e átomos de cobre por molécula de proteína

\begin{tabular}{lcccc}
\hline Amostras & Spot & $\begin{array}{c}\mathrm{N}^{\circ} \text { de moléculas } \\
\text { de proteína }\left(10^{13}\right)\end{array}$ & $\begin{array}{c}\mathrm{N}^{\circ} \text { de átomos } \\
\text { de cobre }\left(10^{14}\right)\end{array}$ & $\begin{array}{c}\text { Átomos de } \\
\text { cobre por } \\
\text { molécula de } \\
\text { proteína }\end{array}$ \\
\hline Plasma & 5 & 7,50 & 1,47 & 1,96 \\
& 12 & 4,50 & 0,94 & 2,10 \\
Músculo & 16 & 2,50 & 0,23 & 0,92 \\
& 13 & 5,30 & 1,03 & 1,94 \\
Fígado & 6 & 7,70 & 0,78 & 1,01 \\
& 21 & 7,00 & 0,73 & 1,04 \\
\hline
\end{tabular}

pode-se inferir que no spot 5 da amostra de plasma cada molécula de proteína contém aproximadamente dois átomos de cobre ligados em sua estrutura. Utilizando-se esse raciocínio, pode-se inferir que em relação aos demais spots das amostras de plasma, músculo e fígado, cada molécula de proteína contém aproximadamente de um a dois átomos de cobre.

\section{CONCLUSÃO}

A utilização da eletroforese 2D-PAGE como etapa inicial no estudo de avaliação de metaloproteínas foi eficiente no fracionamento das proteínas presentes em amostras de plasma, músculo e tecido hepático de tilápia do Nilo (Oreochromis niloticus). A boa correlação obtida nas repetições dos geis indicou que os procedimentos de extração de proteínas totais preservaram a estrutura metal-proteína, o que possibilitou o mapeamento de cobre nos spots proteicos por SR XRF e posterior quantificação desse elemento por GFAAS. A quantificação do cobre nos spots proteicos permitiu se fazer uma estimativa do número de átomos desse elemento por molécula de proteína, verificando-se que todas as proteínas dos spots proteicos estudados apresentam proporções de um a dois átomos de cobre por molécula de proteína, indicando, assim, que se pode tratar de metaloproteínas.

\section{REFERENCIAS}

1. Knox, D.; Cowey, C. B.; Adron, J. W.; Aquaculture 1982, 27, 111.

2. Gatlin, D. M.; Wilson, P. W.; Aquaculture 1986, 52, 191.

3. Neves, R. C. F.; Moraes, P. M.; Silva, F. A.; Loureiro, V. R.; Saleh, M. A. D.; Padilha, C. C. F.; Barros, M. M.; Padilha, P. M.; Sens. Instrumen. Food Qual. 2008, 2, 274.

4. Neves, R. C. F.; Moraes, P. M.; Saleh, M. A. D.; Loureiro, V. R.; Silva, F. A.; Barros, M. M.; Padilha, C. C. F.; Jorge, S. M. A.; Padilha P. M.; Food Chem. 2009, 113, 679.

5. Sá, M. V. C.; Pezzato, L. E.; Barros, M. M.; Padilha P. M.; Aquaculture 2004, 238, 385.

6. Sá, M. V. C.; Pezzato, L. E.; Barros, M. M.; Padilha P. M.; Aquac. Nutr. 2005, 11, 273.

7. Silva, F. A.; Neves, R. C. F.; Quintero-Pinto, L. G.; Padilha, C. C. F.; Jorge, S. M. A.; Barros, M. M.; Pezzato, L. E.; Padilha P. M.; Chemosphere 2007, 68, 1542.

8. Loureiro, V. R.; Saleh, M. A. D.; Moraes, P. M.; Neves, R. C. F.; Padilha, C. C. F.; Padilha P. M.; J. Braz. Chem. Soc. 2007, 18, 1235.

9. Silva, F. A; Padilha, C. C. F.; Pezzato, L. E.; Barros, M. M.; Padilha P. M.; Talanta 2006, 69, 1025.

10. Haraguchi, H.; J. Anal. At. Spectrom. 2004, 19, 5.

11. Szpunar, P.; Anal. Bioanal. Chem. 2004, 378, 54. 
12. Gòmez-Ariza, J. L.; Garcia-Barrera, T.; Lorenzo, F.; Bernal, V.; Villegas, M. J.; Oliveira, V.; Anal. Chim. Acta 2004, 524, 15.

13. Garcia, J. S.; Magalhães, C. S.; Arruda, M. A. Z.; Talanta 2006, 69, 1.

14. Lima, P. M.; Neves, R. C. F.; Santos, F. A.; Pérez, C. A.; Silva, M. A. O.; Arruda, M. A. Z.; Castro, G. R.; Padilha, P. M.; Talanta 2010, 82, 1056.

15. Santos, F. A.; Lima, P. M.; Neves, R. C. F.; Moraes, P. M.; Pérez, C. A.; Silva, M. A. O.; Arruda, M. A. Z.; Castro, G. R.; Padilha, P. M.; Microchim. Acta 2011, 173, 49.

16. Hames, B. D.; Rickwood, D.; Gel Electrophoresis of proteins: A practical approach; $2^{\text {nd }}$ ed., IRL Press: New York, 1990, p. 383.

17. Berkelman, T.; Stenstedt, T.; 2-D Electrophoresis: Principles and Methods, Amersham Biosciences: Uppsala, 1998, p. 101.

18. Lanças, F. M.; Silva, J. C. R.; Bicudo, R. C.; Neto, M. B.; Analytica 2003, 6,60 .

19. Bradford, M. M.; Anal. Biochem. 1976, 72, 248.

20. Candiano, G.; Bruschi, M.; Musante, L.; Santucci, L.; Ghiggeri, G. M.; Carnemolla, B.; Orecchia, P.; Zardi, L.; Righetti, P. G.; Electrophoresis 2004, 25, 1327.
21. Weseloh, G.; Kuhbacher, M.; Bertelsmann, H.; Ozaslan, M.; Kyriakopoulos, A.; Knochel, A.; Behne, D.; J. Radioanal. Nuclear Chem. 2004, 259, 473.

22. Saleh, M. A. D.; Neves, R. C. F.; Silva, F. A.; Moraes, P. M.; Loureiro, V. R.; Roldan, P. S.; Padilha, P. M.; Food Anal. Meth. 2009, 2, 162.

23. Garcia, J. S.; Sousa, G. H. M. F.; Eberlin, M. N.; Arruda, M. A. Z.; Metallomics 2009, 1, 107.

24. Verbi, F. M.; Arruda, S. C. C.; Rodríguez, A. P. M.; Pérez, C. A.; Arruda, M. A. Z.; J. Biochem. Biophys. Meth. 2005, 62, 97.

25. Sussulini, A.; Garcia, J. S.; Mesko, M. F.; Moraes, D. P.; Flores, E. M.; Pérez, C. A.; Arruda, M. A. Z.; Microchim. Acta 2007, 158, 173.

26. Wind, M.; Lehamann, W. D.; J. Anal. At. Spectrom. 2004, 19, 20.

27. Padilha, C. C. F.; Moraes, P. M.; Garcia, L. A.; Pozzi, C. M. C.; Lima, G. P. P.; Valente, J. P. S.; Jorge, S. M. A.; Padilha, P. M.; Food Anal. Meth. 2011, 4, 325 . 